Special Issue on Violence against Individuals and Communities: Reflecting on the Trayvon Martin Case [This article appears in the Scholarship, Science and Practice section of the Special Issue]

\title{
Talking about the Trayvon Martin Case in Psychology and Counseling Training and Psychotherapy
}

\author{
Sannisha K. Dale \\ Boston University \\ Jessica Henderson Daniel \\ Children's Hospital Boston
}

\begin{abstract}
The Trayvon Martin tragedy (the shooting of a Black male adolescent in a Florida gated community) was covered frequently by media outlets for a few months before the level of coverage gradually became only periodic updates on the status of the case and court proceedings. In response to the coverage, the listserv of the American Psychological Association (APA) Division 45 (Society for the Psychological Study of Ethnic Minority Issues) became a site for sharing information about the case, resources, comments and recommendations. Inspired by one of the comments regarding the importance of taking action in the form of conversations and dialogues in counseling and psychology training settings and psychotherapy, this article (1) reviews guidelines such as the APA Guidelines on Multicultural Education, Training, Research, Practice, and Organizational Change for Psychologists, (2) notes applicable literature on the importance of promoting discussions about multicultural issues in training settings and psychotherapy, (3) describes examples of discussions held in training settings following the tragedy, and (4) lists several recommendations for facilitating conversations about the tragedy.
\end{abstract}

Keywords. Trayvon Martin, Psychology and Counseling Training, Psychotherapy, Racial Profiling, Racism 


\section{Introduction}

Trayvon Martin was killed on February 26, 2012, and his death was covered by major media outlets for a few months before the media coverage decreased. During this period, psychologists, counselors and laypersons watched, listened and voiced their opinions and reactions to the tragedy. Although the facts of the case are yet to be determined in court, the information released to the public left many questioning whether racial profiling contributed to the tragedy. Trayvon was described as a 17-year-old unarmed Black male adolescent who was walking in a gated community. He was wearing a gray hoodie and carrying a bag of skittles and ice tea. The accused, George Zimmerman was acting as a neighborhood watch captain and told the 911 dispatcher that Trayvon "looks like he's up to no good". Was Trayvon deemed suspicious because he was a Black male adolescent? In addition, several factors raised the question of whether the case would have been handled differently if the victim were a White adolescent. First, there was a lack of an immediate investigation by the Sanford Police Department (the city in which he was killed). Second, there was a long delay in arresting and charging George Zimmerman, in other words, he was arrested and charged with second-degree murder on April 11, 2012, approximately six weeks after the death of Trayvon Martin. Third, shortly after his arrest, Mr. Zimmerman was released on bail. The listserv of the American Psychological Association (APA) Division 45 (Society for the Psychological Study of Ethnic Minority Issues) became a site for psychologists and student members to share information, resources, comments and recommendations with each other regarding the case. This paper expands on one of the comments regarding the importance of taking action in training settings (e.g. graduate classes and internship seminars) and therapy to bring about greater multicultural competency and awareness of the threat of racial profiling and death faced by ethnic minority adolescents and adults as well as the overall negative impact of racism on individuals from ethnic minority groups and White persons. In doing so, this article (a) reviews the applicable guidelines and literature, (b) describes actual examples of action taken in training settings, and (c) lists several recommendations for talking about the Trayvon Martin Case in psychology and counseling training programs and psychotherapy.

\section{Background Literature APA Guidelines}

In February 2001, APA issued the "APA Resolution on Racial/Ethnic Profiling and Other Racial/Ethnic Disparities in Law and Security Enforcement Activities" that briefly highlights background information on racial/ethnic profiling and states APA's stance (2001). Below are two excerpts from that document:

Whereas some law and security enforcement officers may use stereotypical notions to determine alleged suspects of criminal behavior in a variety of circumstances including: traffic stops, border stops, "out of place" stops such as questioning of racial/ethnic minorities in predominantly White suburban areas and in other locations and venues where law and security officers might perceive ethnic minorities as being "out of place", disturbances in education environments, and other situations where local, state, or federal law and security enforcement have independent decision making authority (American Civil Liberties Union, 1999; American Psychological Association, 2000; Bachman, 1996; Government Accounting Office, 2000; Harris, 1997; Irving, 1989). 
(para. 4) The American Psychological Association (APA) advocates for and encourages research efforts to investigate: (a) the role of racial/ethnic bias and stereotyping in traffic stops, other law enforcement activities, and security activities (e.g., airport and border security); (b) the prevalence of racial/ethnic profiling and racial/ethnic disparities in law enforcement and security activities; and (c) related effects on individuals, communities of color, and law and security enforcement officers and agencies. (para. 8)

This resolution is relevant to the Trayvon Martin case because it is possible that while acting in the role of a neighborhood watch captain, George Zimmerman used stereotypical notions (i.e. Black male adolescent wearing a hoodie) to determine that Trayvon was suspicious and initiated an interaction that ended in the teen's death. It is also feasible that because Trayvon was perceived as being out of place in the gated community, following his death the Sanford Police Department failed to canvas the neighborhood to inquire if anyone knew Trayvon or to use Trayvon's phone to find his parents or locate anyone who might know him. Instead, Trayvon's body was labeled as a John Doe until his father filed a missing person's report the next day. Given the possible racial profiling and the inadequate response by law enforcement, this case is relevant to the APA Resolution on Racial/Ethnic Profiling and Other Racial/Ethnic Disparities in Law and Security Enforcement Activities (APA, 2001). Consequently, graduate students, interns, fellows, practitioners, faculty, trainers, and others should at the very least create a dialogue about the Trayvon Martin case and its relevance to our research, training and practice.

Also of relevance to the case is the APA Guidelines on Multicultural Education, Training, Research, Practice, and Organizational Change for Psychologists (2003) that highlights the need for psychologists to address multiculturalism in these contexts. Specifically, the article provides and elaborates on the six following guidelines:

1. "Psychologists are encouraged to recognize that, as cultural beings, they may hold attitudes and beliefs that can detrimentally influence their perceptions of and interactions with individuals who are ethnically and racially different from themselves" (p. 382).

2. "Psychologists are encouraged to recognize the importance of multicultural sensitivity/responsiveness to, knowledge of, and understanding about ethnically and racially different individuals" (p. 385).

3. "As educators, psychologists are encouraged to employ the constructs of multiculturalism and diversity in psychological education" (p. 386).

4. "Culturally sensitive psychological researchers are encouraged to recognize the importance of conducting culture-centered and ethical psychological research among persons from ethnic, linguistic, and racial minority backgrounds" (p. 388).

5. "Psychologists are encouraged to apply culturally appropriate skills in clinical and other applied psychological practices" (p. 390).

6. "Psychologists are encouraged to use organizational change processes to support culturally informed organizational (policy) development and practices" (p. 392).

The Trayvon Martin case can be used in training to draw divergences or parallels between the characters and experiences of Trayvon Martin and George Zimmerman with psychologists and graduate students in clinical context. For instance, most of us in the United States (both White persons and individuals who belong to ethnic minority groups) were socialized to view Black male adolescents and adults as inferior and dangerous, stereotypes that have negative and in 
some cases deadly consequences for Black male adolescents and adults and other ethnic minorities. Recognizing this and addressing it via discussions about the Trayvon Martin case can increase our understanding of ourselves and ethnically and racially different persons as well as improve our competency to work with diverse individuals.

\section{Training Settings}

The APA Guidelines on Multicultural Education, Training, Research, Practice, and Organizational Change for Psychologists (2003) emphasizes the importance of cultural competency for psychologists and graduate students in training, however this goal is yet to be achieved. According to Sanchez-Hucles and Jones (2005), barriers include colorblindness, misconception that racism does not negatively impact White Americans, low awareness of white privilege, belief that ethnic minorities are automatically culturally competent, and faculty and supervisors who have little training in multiculturalism and do not know how to talk about racial and ethnic differences. Nonetheless it is important to work through these barriers and promote cultural competency.

Discussing the Trayvon Martin case in training settings can bring awareness of modern racism as not simply a covert act but as a "reality-based and repetitive trauma" (Daniel, 2000, p. 126). As important would be identifying possible reasons for some resistance to talking about race (Tatum, 1992). In discussing the case, there needs to be an acknowledgment that persons of color experience daily microaggressions. Racial and ethnic microaggressions are everyday insults, comments and behaviors by sometimes well-intended White people that convey a message of oppression and inferiority to people of color (Sue, 2010). The negative impact of racism on individuals of color in the United States has been documented, researched and published (Brondolo, Gallo, \& Myers, 2009; Casagrande, Gary, LaVeist, Gaskin, \& Cooper, 2007; Constantine, 2006; Helms, 2005; Steele \& Aronson, 1995; Wang, Leu, \& Shoda, 2011). For instance, in a sample of predominantly Latino and African American youth, researchers found that all the racial and ethnic groups reported high rates of perceived racism (range $80 \%$ to $32.4 \%$ ) that was significantly correlated with environmental risks (e.g. violence), behavioral risks (e.g. drug use) and worry (Surko, Ciro, Blackwood, Nembhard, \& Peake, 2005). Similarly, a meta-analysis on the relationship between perceived racism and mental health among Black American adults found a positive correlation between perceived racism and psychological distress (Pieterse, Todd, Neville, \& Carter, 2012).

However, the negative impact of racism on White persons is less discussed. Beginning with Bowser and Hunt's first edition of Impacts of Racism on White Americans (1981) discussing social and cultural ways that racism negatively affects Whites persons, scholars have continued to conceptualize and explore the costs of racism to Whites persons (Bowser, 1996; Kivel, 2011; Spanierman \& Heppner, 2004; Spanierman et al., 2008; Todd, Spanierman, \& Poteat, 2011). Kivel noted the loss of culture and distorted views of history, safety and danger. Spanierman and Heppner conceptualized the psychological costs of racism to White persons as falling into three dimensions- affective (i.e., negative emotional consequences), cognitive (i.e., distorted view of self, others, and reality), and behavioral dimensions (i.e., limited or restricted actions). A qualitative study by Spanierman et al. examining White university students reactions to racism found that their responses fell into three similar dimensions: affective (e.g. empathetic 
reactions and guilt), social (limited exposure to people of other races and fear in relationships with people of other races), and cognitive (e.g. distortion of racism and White Privilege).

As noted previously, a barrier to the active promotion of cultural competency within psychology and counseling training programs are faculty and supervisors who have little training in multiculturalism and who consequently do not know how to talk about racial and ethnic differences (Sanchez-Hucles \& Jones, 2005). Both White faculty and faculty of color have written about experiences and themes from teaching about White privilege, racism and diversity in university settings (Gillespie, Ashbaugh \& DeFiore, 2002; Heinze, 2008; Rich \& Cargile, 2004; Tatum, 1992, 1994; Tummala-Narra, 2009). For instance, Heinze, as a White heterosexual male faculty, described themes he covered as well as tools and exercises he used in teaching about White privilege and racism in the context of a multicultural psychology course. These works can be a great resource for psychology and counseling faculty as they plan to facilitate a discussion about the Trayvon Martin case.

Creating dialogues about race, ethnicity and oppression in the wake of incidents such as Trayvon Martin's death can be a way to combat racism and offer students more training around social justice issues. Miller and Sendrowitz (2011) found that while counseling psychology trainees expressed an interest and commitment to social justice in their profession, only $30 \%$ believed that their training program allocated enough resources, time and guidance needed for them to engage in social justice advocacy. Similarly, Beer, Spanierman, Greene and Todd (2012) found that students wanted more training in social justice than what they experienced in their programs and their views of their training context predicted their commitment to social justice. Dialogues about race and ethnicity can be one form of social justice training. In a school of social work, Miller and Donner (2000) facilitated a race dialogue consisting of graduate students, faculty and staff. Almost $100 \%$ of the participants felt that the racial dialogue had been helpful. Also, many participants ( $92.7 \%$ of White persons and $45.5 \%$ of people of color) agreed that they were motivated to become more involved in antiracism efforts as a result of the dialogue.

\section{Psychotherapy}

Beyond the training seminars, classes and supervision, taking the Trayvon Martin case into therapy is also important. This is not just simply acknowledging the media coverage; it is also validating the pain felt by ethnic minority communities as well as costs experienced by White individuals (Daniel, 2000; Spanierman et al., 2008). When a person is harmed, possibly due to racial profiling, it sends ripples of hurt among ethnic minorities whose sense of safety and worth is undermined and whose memories and stories of acts of racism may resurface (Daniel, 2000). Among some White clients, Trayvon Martin's case may also cause disbelief or denial about racial violence in today's society and further shatter the myth of a postracial society in the era of President Barack Obama (Bonilla-Silva \& Dietrich, 2011; Kivel, 2011; Wise, 2010).

Both White and ethnic minority trainees may struggle with discussing racial and ethnic issues in therapy. Daniel (2000) noted that the topic of race may be avoided because the therapist may believe that racism no longer exists, or that racism is merely an excuse for not succeeding. Frankenberg (1993), through interviews with White women, found that many White respondents were unaware of racial themes in their own lives. She found that the interview 
questions reminded them about previous experiences and messages about race that they had forgotten. Her analyses suggest that "thinking through race" can foster an understanding of racism and its impact on oneself in a racially positioned society. A focus group study that explored the reactions of White counselor trainees to racial issues in therapy and supervision found major themes of White racial consciousness (i.e. awareness of one's race in the interactions and/or minimizing race as an issue) and discomfort with racial issues (e.g. anxiety, agitation and confusion) (Utsey, Gernat, \& Hammar, 2005).

Authors have acknowledged the challenges around talking about race and ethnicity in therapy and have made useful recommendations. For instance, Cardemil and Battle (2003) offer several guidelines to generate conversations about race and ethnicity in therapy. These guidelines include (a) recognizing that there is diversity within racial/ethnic groups; (b) acknowledging that clients may be different in some ways from other members of their group; and, (c) accepting that clients' and therapists' experiences may be impacted by power, privilege and racism.

Jernigan and Daniel (2011) propose a strength-based approach for assessment and treatment of racial trauma in Black children and adolescents. They argue that racial socialization and racial identity development are integral to understanding the lives of Black persons. Zayas (2001) describes three cases to illustrate how struggles with racism and ethnic identity can be incorporated in therapy with minority adolescents. In each case, struggles with racism and ethnic identity became salient when the therapist appropriately and purposely asked questions in order to clarify various struggles (e.g. peer group relations). Erskine (2002) also offers a review of a therapy case with a biracial (African and White) adolescent in which racial differences, racial identity and the effects of racism were integrated. In group therapy contexts, discussion of the Trayvon Martin case is also important because clients of various ethnic identities in the group may be affected by the media coverage of the incident which may in turn impact their emotions and behaviors in the group. Weiss's (2005) chapter provides an overview on the nature of hate crimes and their effects on victims and discusses the implications for group work.

It is important to note that it is not the responsibility of the client to lead in the discussion of race and racism; instead, it is the responsibility of the therapist to take the lead in individual or group sessions because clients of color may not do so due to perceived risks. For instance, African American male veterans did not feel comfortable discussing race in a majority White group because of responses including silence, changing of topic and implications of paranoia or exaggeration (Jones, Brazel, Peskind, Morelli \& Raskind, 2000). However, in an all African American group these veterans reported that they felt that their experiences of racism would be responded to with empathy and validation.

Sometimes clients of color may be reluctant to bring race into the session because they seek to protect themselves and the therapist by self-censoring (Daniel, 2000). Clients may also avoid discussing matters that may reinforce stereotypes associated with their racial or ethnic group. Also they may decline to reveal examples of White perpetrator/Black victim situations for fear of making the White therapist uncomfortable. In addition, there can be an unspoken collusion between clients of color and a White therapist to exclude race and racism from the session due to discomfort by both parties (Daniel, 2000; Utsey, Gernat, \& Hammar, 2005). For the White therapist, the goal may be to avoid possible feelings of guilt, shame or anger; for the clients of 
color, they may seek to protect their White therapists from such feelings, to maintain the therapeutic relationship and to hide their own feelings (Daniel; Spanierman \& Heppner, 2004; Spanierman et al., 2008). Nonetheless, it is important to work through the reluctance and create a therapeutic space for clients to safely discuss issues around race and ethnicity as encouraged by the APA Guidelines on Multicultural Education, Training, Research, Practice, and Organizational Change for Psychologists (APA, 2003).

\section{Examples of Discussions in Training Settings}

Creating a space in therapy for clients to discuss issues around race and ethnicity is important, but it is equally important to have conversations in training settings with graduate students as well as psychology interns and fellows. In the wake of the Trayvon Martin death and the news coverage, Dr. Jessica Henderson Daniel, Director of Training in Psychology at Children's Hospital Boston, initiated conversations with psychology interns and fellows about the case which resulted in discussions centered on themes including (a) interns' lack of awareness that racial profiling and the negatives consequences might be an issue in the lives of some of their adolescent patients; (b) how teens might respond if stopped by the police while walking or standing with other teens and driving a car; (c) unfairness of the vulnerability and the resulting anger and rage that the adolescents may feel; and, (d) how that anger can spill over into relationships with adults in authority positions. While the interns were better informed, these discussions are not sufficient for them to develop multicultural competency. Instead multicultural competency has to be cultivated throughout graduate and post-graduate trainings; it is an on-going process. Nonetheless, given the media coverage of the Trayvon Martin case, it was important to have discussions about the case and its relevance to the lives of the interns and patients they serve. Beyond starting conversations within her training setting, Dr. Daniel circulated the APA Resolution on Racial/Ethnic Profiling and Other Racial/Ethnic Disparities in Law and Security Enforcement Activities (APA, 2001) and forwarded an email from Dr. Norweeta Milburn on the APA Division 45 listserv calling for action (excerpt below).

On Mar 18, 2012, at 5:08 PM, Norweeta Milburn wrote:

Dear Division 45,

As we are thinking about going to Orlando, FL for the APA convention this year, is there anything that we and APA can do to support the request of Trayvon Martin's parents that the Justice Department investigate the killing of their unarmed 17 years old son by an adult who thought he looked "suspicious"? Trayvon Martin was Black and the adult who shot him has claimed self-defense under FL's "Stand Your Ground" law. FL's "Stand Your Ground" law allows for immunity if someone "feels reasonable fear that they will be killed or seriously injured" (NY Times, 3/17/12). Trayvon had on a hoodie and was carrying skittles and a bottle of ice tea. The community where Trayvon was shot is close to Orlando.

It seems in this instance that a full investigation is in order. Should we not make our voices heard in support of justice? I would like for the EC to consider what can be done by APA, hope that other Division members are in support of this request, and that maybe the Divisions for Social Justice will also take up this issue. Perhaps APA could 
provide a letter supporting the family's request that the Department of Justice investigate? Saturday's, March 17th, New York Times has an article and op-ed piece on this killing, and they are available on-line. The story has also been covered by ABC News and papers in FL.

Thank you,

Norweeta Milburn

In addition, as Adjunct Faculty in the Clinical Psychology Program at Boston University where she teaches a course on Social Oppression, Dr. Daniel suspended the scheduled topic and instead introduced the topic of racial profiling and the resulting vulnerability of some groups in our society. It was helpful that the class had already read about racial profiling in Frank Wu's book Yellow (2002). Similarly, Sannisha Dale, instructor for Abnormal Psychology in the Boston University Metropolitan College, integrated a discussion about the case with her lesson on Schizophrenia by (a) having students share their knowledge of and feelings about the case; (b) sharing a clinical case about a Black man who was misdiagnosed with Schizophrenia, Paranoid Type when his reported experience of being watched very closely in his majority White workplace was interpreted as paranoia by the assessing White clinician; and, (c) facilitating a discussion in which the students shared thoughts about differentiating when behaviors that also serve as criteria symptoms for schizophrenia are normal versus abnormal and the intersections with race, ethnicity and culture.

\section{Summary and Recommendations}

In summary, Trayvon Martin's death and the circumstances surrounding his death initially received widespread media coverage sparking discussions among psychologists and laypersons about racial profiling, racial trauma and multicultural issues. A comment by Dr. Jessica Henderson Daniel via the APA Division 45 list serve regarding the importance of taking action in the form of conversations and dialogues in psychology training settings and psychotherapy served as the inspiration for this article in which we have (1) reviewed guidelines such as the APA Guidelines on Multicultural Education, Training, Research, Practice, and Organizational Change for Psychologists (APA, 2003); (2) referred to applicable literature on the importance of promoting discussions about multicultural issues in training settings and psychotherapy; and, (3) described examples of discussions initiated in training settings following the tragedy. Below

we list several recommendations for facilitating conversations about the tragedy of Trayvon Martin's death in psychology and counseling training and psychotherapy.

\section{Psychology and Counseling Training}

- Recognize that talking about the vulnerability of ethnic minority individuals to racial profiling and trauma is not hyperbole - it is real. Ethnic minority individuals are subjected to racial profiling in their everyday lives.

- Make a concerted effort to work through barriers to promoting cultural competency and talking about racial and ethnic differences and create a dialogue about tragedies such as Trayvon Martin's death. 
- Refer to literature written about experiences and themes from teaching about racism, White privilege, and diversity in university settings by both White faculty and faculty of color in planning facilitation of a discussion about the Trayvon Martin case.

- Use the Trayvon Martin case in training to draw divergences or parallels between the characters and experiences of Trayvon Martin and George Zimmerman with psychologists, graduate students and clients.

- Create dialogues about race, ethnicity and oppression in the wake of incidents such as Trayvon Martin's death as a way to combat racism and offer students more training around social justice issues.

- While some lectures, seminars or courses are more easily amenable to integrating a discussion about racial profiling and tragedies such as Trayvon Martin, in other classes it may be worthwhile to suspend the planned topic and discuss the case.

- During conversations about the case with trainees, try to identify possible reasons for resistance to talking about race.

\section{Psychotherapy}

- Acknowledge that clients' and therapists' experiences may be impacted by power, privilege and racism. Both White and ethnic minority trainees may struggle with discussing racial and ethnic issues in therapy. Scholars have acknowledged the difficulty experienced by some when talking about race and ethnicity in therapy and have made useful recommendations.

- Take the lead in the discussion of race and racism in individual or group sessions because clients of color may not do so due to perceived risks. It is important to note that it is not the responsibility of the client to lead; instead it is the responsibility of the therapist.

- In therapy, validate the pain felt by ethnic minority clients as well as costs experienced by White people in the wake of the Trayvon Martin case; and acknowledge that in their daily lives, persons of color experience daily microaggressions and White people feel the negative impacts of racism.

- Consult and read literature that provides case examples of how issues on racism and ethnic identity can be integrated into therapy.

Trayvon Martin's unfortunate death provides an opportunity for faculty and students in psychology and counseling to engage in critical conversations about the circumstances surrounding his tragedy and the implications for training and psychotherapy. Conversations about racial profiling and racism are never easy to have, however we hope that the noted recommendations are useful in generating discussions about the Trayvon Martin case because we owe it to the fields of psychology and counseling and the millions that we serve to engage in these important dialogues. 


\section{Contact information:}

Sannisha K. Dale

Department of Psychology

Boston University

648 Beacon Street, Boston, MA 02215

E-mail: sannishadale@gmail.com.

\section{References}

American Civil Liberties Union. (1999, May). Driving while Black: Racial profiling on our nation's highways. New York: Author.

American Psychological Association. (2000, August). APA fact sheet: Psychology and law enforcement roundtable. Washington, D.C.: Author.

American Psychological Association. (2001). APA Resolution on Racial/Ethnic Profiling and Other Racial/Ethnic Disparities in Law and Security Enforcement Activities. Washington, DC. Retrieved from http://www.apa.org/about/governance/council/policy/racial-profiling.aspx

American Psychological Association. (2003). Guidelines on multicultural education, training, research, practice, and organizational change for psychologists. American Psychologist, 58(5), 377-402. doi: 10.1037/0003-066x.58.5.377

Beer, A. M., Spanierman, L. B., Greene, J. C., \& Todd, N. R. (2012). Counseling psychology trainees' perceptions of training and commitments to social justice. Journal of Counseling Psychology, 59(1), 120-133. doi: 10.1037/a0026325

Bachman, R. (1996). Victim's perceptions of initial police responses to robbery and aggravated assault: Does race matter? Journal of Quantitative Criminology, 12(4), 363-390. doi: $10.1007 / B F 02354424$

Bonilla-Silva, E. \& Dietrich, D. (2011). The sweet enchantment of color-blind racism in Obamerica. The ANNALS of the American Academy of Political and Social Science, 634(1), 190-206. doi: 10.1177/0002716210389702

Bowser, B. P., \& Hunt, R. G. (Eds.). (1981). Impacts of racism on White Americans. Beverly Hills, CA: Sage.

Bowser, B. P., \& Hunt, R. G. (Eds.). (1996). Impacts of racism on White Americans (2nd ed.). Thousand Oaks, CA: Sage.

Brondolo, E., Gallo, L. C., \& Myers, H. F. (2009). Race, racism and health: Disparities, mechanisms, and interventions. Journal of Behavioral Medicine, 32(1), 1-8. doi: $10.1007 / \mathrm{s} 10865-008-9190-3$ 
Cardemil, E. V., \& Battle, C. L. (2003). Guess who's coming to therapy? Getting comfortable with conversations about race and ethnicity in psychotherapy. Professional Psychology: Research and Practice, 34(3), 278-286. doi: 10.1037/0735-7028.34.3.278

Casagrande, S. S., Gary, T. L., LaVeist, T. A., Gaskin, D. J., \& Cooper, L. A. (2007). Perceived discrimination and adherence to medical care in a racially integrated community. Journal of General Internal Medicine, 22(3), 389-395. doi: 10.1007/s11606-006-0057-4

Constantine, M. G. (2006). Institutional racism against African Americans: Physical and mental health implications. In M. G. Constantine \& D. W. Sue (Eds.), Addressing racism: Facilitating cultural competence in mental health and educational settings. (pp. 33-41). Hoboken, NJ US: John Wiley \& Sons Inc.

Daniel, J. H. (2000). The courage to hear: African American women's memories of racial trauma. In L. C. Jackson \& B. Greene (Eds.), Psychotherapy with African American women: Innovations in psychodynamic perspective and practice. (pp. 126-144). New York, NY US: Guilford Press.

Erskine, R. (2002). Exposing racism, exploring race. Journal of Family Therapy, 24(3), 282-297. doi: $10.1111 / 1467-6427.00217$

Frankenberg, R. (1993). White women, race matters: The social construction of Whiteness. Minneapolis, MN US: University of Minnesota Press.

Gillespie, D., Ashbaugh, L., \& DeFiore, J. (2002). White women teaching White women about White privilege, race cognizance, and social action: Toward a pedagogical pragmatics. Race, Ethnicity and Education, 5(3), 237- 253. doi:10.1080/1361332022000004841

Harris, D.A. (1997). "Driving while Black" and all other traffic offenses: The Supreme Court and pretextual traffic stops. Journal of Criminal Law and Criminology, 87(2), 544.

Heinze, P. (2008). Let's talk about race, baby: How a White professor teaches White students about White privilege and racism. Multicultural Education, 16(1), 2-11.

Helms, J. E. (2005). Stereotype threat might explain the Black-White test-score difference. American Psychologist, 60(3), 269-270. doi: 10.1037/0003-066x.60.3.269

Irving, P. J. (1989). Minority group threat, crime, and policing: Social context and social control. New York: Praeger.

Kivel, P. (2011). Uprooting racism: How White people can work for racial justice ( $3^{\text {rd }}$ ed.). Canada: New Society Publishers.

Jernigan, M. M., \& Daniel, J. H. (2011). Racial trauma in the lives of Black children and adolescents: Challenges and clinical implications. Journal of Child \& Adolescent Trauma, $4(2), 123-141$. doi: 10.1080/19361521.2011.574678 
Jones, L., Brazel, D., Peskind, E. R., Morelli, T., \& Raskind, M. A. (2000). Group therapy program for African-American veterans with posttraumatic stress disorder. Psychiatric Services, 51(9), 1177-1179. doi: 10.1176/appi.ps.51.9.1177

Milburn, N. (2012, March 18). Re: [DIV45] Case of Trayvon Martin, FL's "Stand Your Ground" law and APA [Electronic mailing list message]. Retrieved from Division 45 of APA List serve DIV45@LISTS.APA.ORG

Miller, J., \& Donner, S. (2000). More than just talk: The use of racial dialogues to combat racism. Social Work with Groups: $A$ Journal of Community and Clinical Practice, 23(1), 31-53. doi: 10.1300/J009v23n01_03

Miller, M. J., \& Sendrowitz, K. (2011). Counseling psychology trainees' social justice interest and commitment. Journal of Counseling Psychology, 58(2), 159-169. doi: 10.1037/a0022663

Pieterse, A. L., Todd, N. R., Neville, H. A., \& Carter, R. T. (2012). Perceived racism and mental health among Black American adults: A meta-analytic review. Journal of Counseling Psychology, 59(1), 1-9. doi: 10.1037/a0026208 10.1037/a0026208.supp

Rich, M., \& Cargile, A. (2004). Beyond the breach: Transforming White identities in the classroom. Race, Ethnicity and Education, 74), 351-365.

Sanchez-Hucles, J., \& Jones, N. (2005). Breaking the silence around race in training, practice, and research. The Counseling Psychologist, 33(4), 547-558. doi: $10.1177 / 0011000005276462$

Spanierman, L.B., \& Heppner, M.J. (2004). Psychosocial costs of racism to Whites scale (PCRW): Construction and initial validation. Journal of Counseling Psychology. 51, 249262. doi: $10.1037 / 0022-0167.51 .2 .249$

Spanierman, L.B., Oh, E., Poteat, V.P., Hund, A.R., McClair, V.L., Beer, A.M., \& Clarke, A.M. (2008). White university students' responses to societal racism: A qualitative investigation. The Counseling Psychologist. 36, 839-870. doi: $10.1177 / 0011000006295589$

Steele, C. M., \& Aronson, J. (1995). Stereotype threat and the intellectual test performance of African Americans. Journal of Personality and Social Psychology, 69(5), 797-811. doi: 10.1037/0022-3514.69.5.797

Sue, D. W. (2010). Microaggressions, marginality, and oppression: An introduction. In D. W. Sue (Ed.), Microaggressions and marginality: Manifestation, dynamics, and impact. (pp. 3-22). Hoboken, NJ US: John Wiley \& Sons Inc.

Surko, M., Ciro, D., Blackwood, C., Nembhard, M., \& Peake, K. (2005). Experience of racism as a correlate of developmental and health outcomes among urban adolescent mental health clients. In K. Peake, I. Epstein \& D. Medeiros (Eds.), Clinical and research uses of 
an adolescent mental health intake questionnaire: What kids need to talk about. (pp. 235-260). Binghamton, NY US: Haworth Social Work Practice Press.

Tatum, B. D. (1992). Talking about race, learning about racism: The application of racial identity development theory in the classroom. Harvard Educational Review, 62(1), 1-24.

Tatum, B. (1994). Teaching White students about racism: The search for White allies and the restoration of hope. Teachers College Record, 95(4), 462-476.

Todd, N.R., Spanierman, L.B., \& Poteat, V.P. (2011)._Longitudinal examination of the psychosocial costs of racism to Whites across the college experience. Journal of Counseling Psychology, 58(4), 508-521. doi:10.1037/a0025066

Tummala-Narra, P. (2009). Teaching on diversity: The mutual influence of students and instructors. Psychoanalytic Psychology, 26(3), 322-334. doi:10.1037/a0016444

U.S. Government Accounting Office. (2000). U.S. Customs Service: Better targeting of airline passengers for personal searches could produce better results. Washington, D.C.: Author.

Utsey, S. O., Gernat, C. A., \& Hammar, L. (2005). Examining White counselor trainees' reactions to racial issues in counseling and supervision dyads. The Counseling Psychologist, 33(4), 449-478. doi: 10.1177/0011000004269058

Wang, J., Leu, J., \& Shoda, Y. (2011). When the seemingly innocuous "stings": Racial microaggressions and their emotional consequences. Personality and Social Psychology Bulletin, 37 (12), 1666-1678. doi: 10.1177/0146167211416130

Weiss, J. C. (2005). Working with victims of hate crimes. In G. L. Greif \& P. H. Ephross (Eds.), Group work with populations at risk (2nd ed.). (pp. 197-211). New York, NY US: Oxford University Press.

Wise, T. (2010). Colorblind: The rise of post-racial politics and the retreat from racial equity. San Francisco, CA US: City Lights Publishers.

Wu, F. H. (2002). Yellow: Race in America beyond Black and White. New York, NY US: Basic Books.

Zayas, L. H. (2001). Incorporating struggles with racism and ethnic identity in therapy with adolescents. Clinical Social Work Journal, 29(4), 361-373. doi: 10.1023/a:1012267230300 